\title{
Next Generation Civil Transport Aircraft Design Considerations for Improving Vehicle and System-Level Efficiency
}

\author{
Diana M. Acosta* \\ NASA Ames Research Center, Moffett Field, California, 94035 \\ Mark D. Guynn ${ }^{\dagger}$ and Richard A. Wahls ${ }^{\ddagger}$ \\ NASA Langley Research Center, Hampton, Virginia, 23681 \\ Rubén Del Rosario ${ }^{\S}$ \\ NASA Glenn Research Center, Cleveland, Ohio, 44135
}

\begin{abstract}
The future of aviation will benefit from research in aircraft design and air transportation management aimed at improving efficiency and reducing environmental impacts. This paper presents civil transport aircraft design trends and opportunities for improving vehicle and system-level efficiency. Aircraft design concepts and the emerging technologies critical to reducing thrust specific fuel consumption, reducing weight, and increasing lift to drag ratio currently being developed by NASA are discussed. Advancements in the air transportation system aimed towards system-level efficiency are discussed as well. Finally, the paper describes the relationship between the air transportation system, aircraft, and efficiency. This relationship is characterized by operational constraints imposed by the air transportation system that influence aircraft design, and operational capabilities inherent to an aircraft design that impact the air transportation system.
\end{abstract}

\section{Nomenclature}

c Thrust specific fuel consumption

$h_{F} \quad$ Fuel heating value

$t \quad$ Time

$C_{D} \quad$ Coefficient of drag

$C_{L} \quad$ Coefficient of lift

$D \quad$ Aerodynamic drag force

$L \quad$ Aerodynamic lift force

$S \quad$ Wing planform area

$V \quad$ Velocity, or airspeed

$W \quad$ Aircraft weight

$W_{f} \quad$ Weight of fuel consumed

$W_{O E W} \quad$ Operational empty weight

$W_{\text {payload }} \quad$ Weight of payload

$W_{\text {totalfuel }} \quad$ Weight of total fuel onboard

$\eta_{P} \quad$ Propulsive efficiency

$\eta_{T} \quad$ Thermal efficiency

$\rho \quad$ Atmospheric density

*Aerospace Engineer, Intelligent Systems Division, Mail Stop 269-1.

$\dagger$ Aerospace Engineer, Aeronautics Systems Analysis Branch, Mail Stop 442, Senior Member AIAA.

$\ddagger$ Project Scientist, Fixed Wing Project, Fundamental Aeronautics Program, Mail Stop 267, AIAA Associate Fellow.

$\S$ Project Manager, Fixed Wing Project, Fundamental Aeronautics Program, Mail Stop 5-3, Senior Member AIAA. 


\section{Introduction}

7 HE aviation industry is vital to the nation's economic well-being. In 2009, civil aviation activity supported 1 1,200,000 Americans with jobs. ${ }^{1}$ That same year, aviation provided the nation with a positive trade value of over $\$ 75$ billion and operations generated a total output of $\$ 296$ billion to the U.S. economy. ${ }^{1}$ Nevertheless, the aviation industry also has a negative impact on the environment and energy usage. In the U.S., air travel fuel use is $7 \%$ of fuel consumed for transportation, and jet fuel produces 65 million metric tons of $\mathrm{CO}_{2}$ per year, which is $4 \%$ of $\mathrm{CO}_{2}$ emission from energy usage in the nation. ${ }^{2}$ Fuel is also approximately $30 \%$ of operating costs for U.S. passenger airlines. ${ }^{3}$

Growth in the aviation industry has been supported over the years through a diverse research and development portfolio in government, industry, and academia. This paper will review what is being done in research at National Aeronautics and Space Administration (NASA) today and could be done in the future to sustain growth in the aviation industry, with a particular focus on improving vehicle and system-level efficiency. First, the paper focuses on vehicle efficiency in Section II. The factors contributing to vehicle efficiency, aircraft design concepts for improved vehicle efficiency, and the emerging technologies critical to reducing thrust specific fuel consumption, reducing weight, and increasing lift to drag ratio are discussed. Next, the paper focuses on system-level efficiency in Section III. The factors contributing to system-level efficiency and the vision for the Next Generation Air Transportation System are discussed. Section IV describes the relationship between the air transportation system, aircraft, and efficiency. This relationship is characterized by operational constraints imposed by the air transportation system that influence aircraft design, and operational capabilities inherent to an aircraft design that impact the air transportation system. Finally, Section V highlights the fact that the impact of aviation extends beyond vehicle and system-level efficiency.

\section{Vehicle Efficiency}

\section{II.A. Factors Contributing to Vehicle Efficiency}

The goal of improving vehicle efficiency corresponds with the goal of reducing fuel usage required to operate an aircraft. The amount of fuel consumed by the aircraft is related to the thrust specific fuel consumption, aircraft weight, and aerodynamic lift and drag forces experienced during operation. Eq. 1 defines the relationship between the weight of fuel consumed and these contributing factors.

$$
W_{f}=\int_{t_{0}}^{t} c W \frac{D}{L} d t
$$

In this equation, $W_{f}$ represents the weight of fuel consumed over time $t_{0}$ to $t, c$ represents the thrust specific fuel consumption, $W$ represents the aircraft weight, $D$ represents the aerodynamic drag force, and $L$ represents the aerodynamic lift force.

The thrust specific fuel consumption, defined as the mass flow rate of fuel over engine thrust, can be represented by

$$
c=\frac{V}{\eta_{P} \eta_{T} h_{F}},
$$

where $V$ is aircraft airspeed, $\eta_{P}$ is propulsive efficiency, $\eta_{T}$ is thermal efficiency, and $h_{F}$ is the fuel heating value. ${ }^{4}$ Some of the emerging technologies in the design of propulsion systems to improve $\eta_{P}$ and $\eta_{T}$ are discussed in Section II.B.3. Aircraft operations also has an impact, with $V$ influencing $c$, Mach influencing $\eta_{P}$, and altitude influencing $\eta_{T}$.

The aircraft weight is a sum of the aircraft's operational empty weight, $W_{O E W}$, the weight of total fuel onboard the aircraft, $W_{\text {totalfuel }}$, and the weight of payload, $W_{\text {payload }}$, as expressed in the following equation:

$$
W=W_{O E W}+W_{\text {totalfuel }}+W_{\text {payload }} .
$$

The $W_{O E W}$ is comprised of the structural weight, propulsion system weight, and weight of equipment required to operate the aircraft, ranging from avionics to passenger seats. The emerging technologies discussed in 
Section II.B.1 strive to reduce $W_{O E W}$. Operators determine the $W_{\text {payload }}$ and $W_{\text {totalfuel }}$ at the beginning of each flight, where the $W_{\text {totalfuel }}$ is planned for the mission as well as extra reserve to accommodate inefficient operations.

The aerodynamic lift and drag forces are defined as

$$
L=\left(\frac{1}{2} \rho V^{2}\right) C_{L} S
$$

and

$$
D=\left(\frac{1}{2} \rho V^{2}\right) C_{D} S
$$

respectively, where $\rho$ is the atmospheric density, $V$ is aircraft airspeed, $C_{L}$ and $C_{D}$ are coefficients of lift and drag, and $S$ is the wing planform area. An aircraft's $S$ and $C_{L}$ and $C_{D}$ characteristics are factors of the aircraft design, and improvements sought are discussed in Section II.B.2. Besides the direct influence of altitude (through $\rho$ ) and $V, L$ and $D$ are also influenced by operations through the values of $C_{L}$ and $C_{D}$. The $C_{L}$ and $C_{D}$ are dependent on attitude (or angle of attack), which is adjusted to provide the required $L$ given the $V$, Mach, vertical profile, and wind conditions.

The total time in operation is another factor in $W_{f}$, since $W_{f}$ is defined as the weight of fuel consumed over time $t_{0}$ to $t$. Inefficient operations, such as rerouting, vectors, holds, and slow speeds while in the air and delays on ground, will increase $t$ for an aircraft's mission, and consequently increase fuel usage and diminish the aircraft's efficiency.

\section{II.B. Emerging Aircraft Design Concepts and Technologies for Vehicle Efficiency}

Advanced aircraft design concept studies have been conducted in recent years to explore the promise of integrated system solutions and motivate research to attain that promise. Studies aimed towards enhancing energy efficiency and environmental compatibility have highlighted the benefits of integrated solutions. Three different aircraft design concepts that have emerged from studies conducted by or funded by NASA include the truss-braced wing configuration, ${ }^{5}$ the hybrid wing body configuration, ${ }^{5-9}$ and the double-bubble configuration. ${ }^{6}$ A conceptual illustration of these configurations is shown in Figure 1. Success of these diverse aircraft design concepts will be dependent on the development of advanced technologies. The research and development of these critical technologies tends to focus in three key challenge areas for improving or maintaining the targeted aircraft efficiency. These three challenge areas include (1) reducing vehicle weight, (2) increasing the ratio of lift over drag, and (3) reducing thrust specific fuel consumption. Emerging technologies and research efforts in each of these challenge areas are discussed in the subsections that follow and highlighted in Figures 2, 3, and 4. Effective design and integration of these emerging technologies will rely on the ability to achieve simultaneous reduction of weight, increase in the ratio of lift over drag, and reduction in thrust specific fuel consumption with minimal impact on other environmental considerations, including noise and emission generation.

\section{II.B.1. Reduce Vehicle Weight}

Vehicle weight will be reduced through the introduction of new structural concepts and designer materials that leverage tailored designs for the vehicle fuselage and wings with integrated control actuators. Research is focused on improving material and structural properties and manufacturability of advanced composites and metals, and on enabling control technologies.

The improvements in composite structures being pursued include the development of design tools and new concepts such as stitched composites and multifunctional skins with composite primary structures. Tailored placement of fibers within composites will optimize structural properties with the aid of new design tools. ${ }^{10}$ Stitching through dry carbon fabric during panel fabrication offers benefits to the structural weight through the replacement of mechanical fasteners, reduction of de-lamination, and improvement in damage tolerance (Fig. 2(a)). Stitched composites also enable the construction of non-circular pressure vessels, which will be essential for some unconventional configurations like the hybrid wing body and the doublebubble. ${ }^{11,12}$ Multifunctional skins will also reduce weight though the combination of lighter gage composite primary structures with other functions that provide protection external to the skin. Among the functions investigated for inclusion in the protective skin are acoustic treatment, thermal insulation, lightning strike protection, impact detection and indication, and ice protection (Fig. 2(b)). ${ }^{10,13}$ 


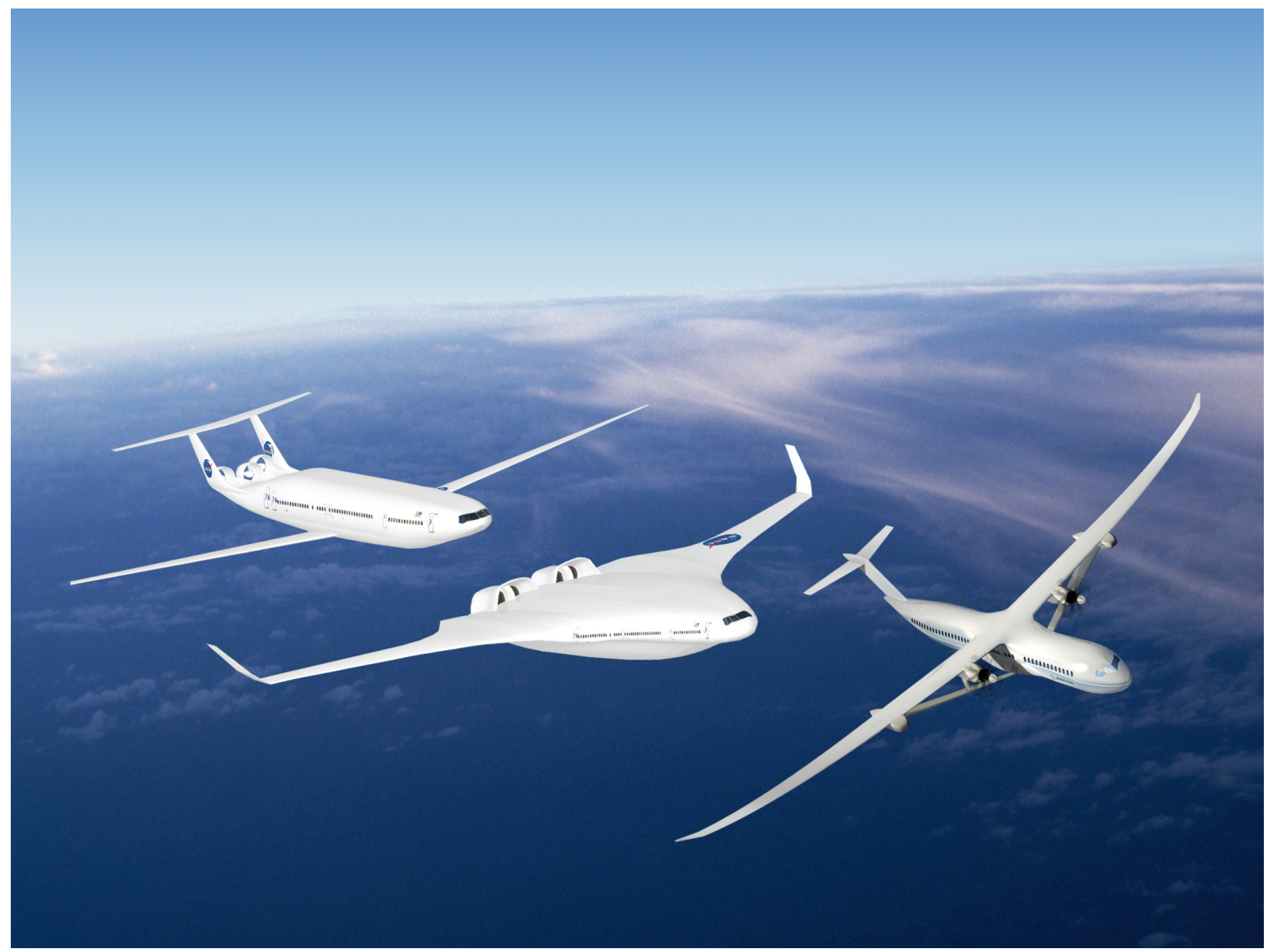

Figure 1. Conceptual illustration of fuel-efficient aircraft, including the truss-braced wing configuration (right), hybrid wing body configuration (center), and double-bubble configuration (left). Image credit: NASA. 
The objective of research for metal structures is to reduce weight through the optimization of load paths using structural concepts like curvilinear stiffeners (Fig. 2(c)), new alloys, and novel manufacturing techniques. ${ }^{10}$ The manufacturing technique explored for this purpose involves additive manufacturing and is envisioned as a replacement for forging (Fig. 2(d)). ${ }^{12,14}$

Active structural control will further reduce wing weight by adjusting the lift distribution and limiting the resulting structural loads during critical maneuvering and gust loads design cases using integrated distributed control actuators (Fig. 2(e)) and new control laws. Control system research under investigation includes techniques for gust load alleviation, load limiting control allocation, modal suppression, and distributed controls. ${ }^{10,15}$

\section{II.B.2. Increase the Ratio of Lift over Drag}

Increasing the ratio of lift over drag will be achieved through reductions in drag. Research emphasis is on reducing viscous drag, induced drag, and wave drag.

One approach to reducing the viscous drag, or friction drag, on an aircraft is the reduction of overall aircraft surface area, or "wetted" area. Configurations such as the hybrid wing body configuration (Fig. 3(a)) are designed towards this goal. Another technique to reduce the aircraft surface area is to reduce the size of stability and control surfaces by increasing their aerodynamic performance through the use of active flow control. As an example, one research effort is evaluating the effectiveness of active flow control to augment rudder performance at low speed conditions (Fig. 3(c)). ${ }^{12,16}$

Viscous drag can also be reduced by preventing large portions of flow from transitioning from laminar to turbulent flow. Since local skin friction increases significantly in turbulent flow, drag is reduced by maintaining a laminar boundary layer. The transition from laminar to turbulent flow is influenced by many factors, including the leading edge wing sweep and Reynolds number. A number of passive and active approaches exists to control the transition. One passive technique under investigation involves discrete roughness elements positioned on the aircraft surface near the leading edge that modify the flow to inhibit or delay transition (Fig. $3(\mathrm{~d})){ }^{12,16,17}$

Induced drag, or the drag created as a result of the lifting force on the aircraft, benefits from efforts to improve the span-wise lift distribution. Aircraft configuration plays a key role. An elliptical span-wise lift distribution attainable through novel configurations, such as the hybrid wing body configuration (Fig. 3(a)), reduces induced drag. Large wing spans and high aspect ratio wings that reduce the span loading also reduce induced drag, and serve as motivation for the truss-braced wing configuration (Fig. 3(b)). Spanwise lift distribution can also be improved in-flight using active controls. One concept to control the lift distribution utilizes active aeroelastic wing shaping control and variable camber continuous trailing edge flaps (Fig. 3(e)). ${ }^{18}$

The reduction of wave drag, or the drag resulting from shocks over the wing upper surface at high subsonic speeds, is being investigated. Researchers are evaluating the ability of circulation control to modify circulation around the aft of the wing during cruise conditions (Fig. $3(\mathrm{f})) .{ }^{15,19}$

\section{II.B.3. Reduce Thrust Specific Fuel Consumption}

Reductions in thrust specific fuel consumption are being pursued through technologies that improve the propulsion system's thermal efficiency and propulsive efficiency, or $\eta_{T}$ and $\eta_{P}$, as seen in Eq. 2. Many of the concepts and technologies have been developed to improve thust specific fuel consumption, but research is needed to enable the concepts and technologies with minimal impact on weight, drag, noise generation, and emission production.

Improved thermal efficiency can be attained through turbomachinery operation at higher pressures and temperatures. One approach is the use of integrated Ceramic Matrix Composites and Environmental Barrier Coating systems for the combustion liner (Fig. 4(a)) and turbine vanes that will allow higher temperatures for new engines and better fuel/air mixing due to a reduction in cooling air flow required. ${ }^{20,21}$ Since high pressure and temperature engine environments also encourage emissions of nitrogen oxides, lean partialmixed combustors and lean direct multi-injection concepts with advanced fuel flow control techniques are also being studied to simultaneously provide fuel efficiency and reduce emission production (Fig. 4(b)). ${ }^{20,22}$

The introduction of advanced ultra-high bypass ratio propulsors and embedded engines with boundary layer ingestion are two strategies being pursued for propulsive efficiency improvement. Open rotor concepts that optimize propulsive efficiency with ultimate bypass ratio are being researched with counter-rotating 


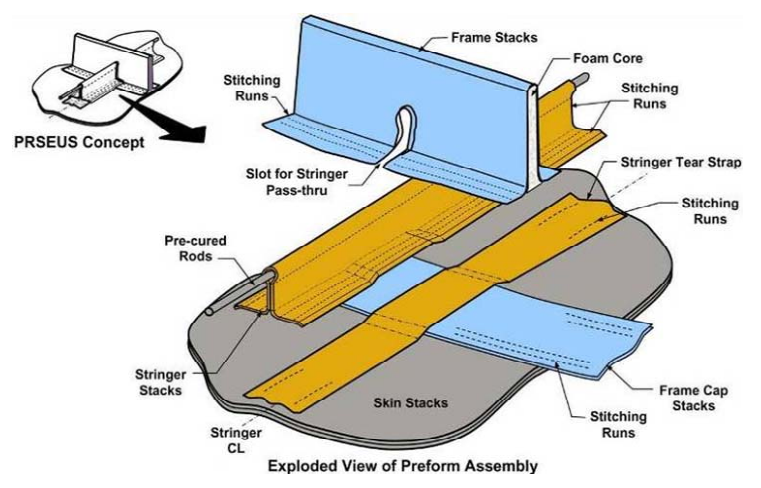

(a) Schematic of the Pultruded Rod Stitched Efficiency Unitized Structure concept for stitched composites. ${ }^{11}$

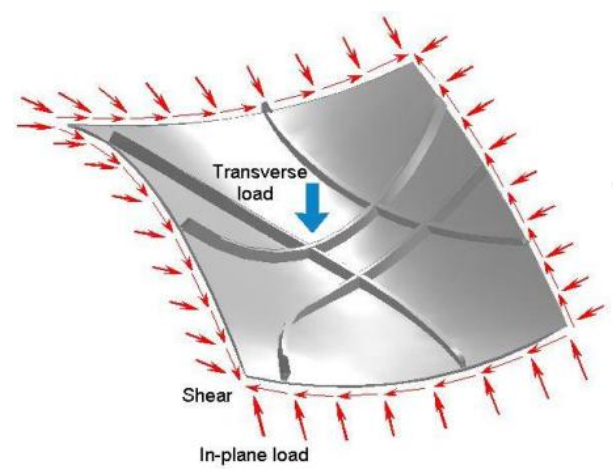

(c) Diagram of a curvilinear stiffener structural concept. ${ }^{10}$

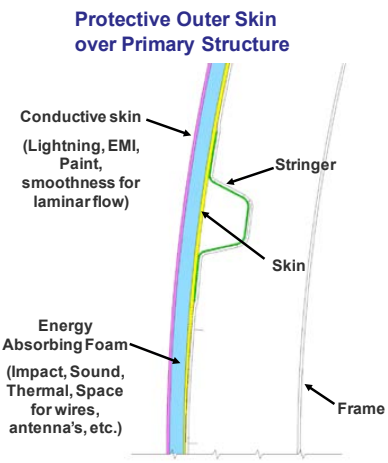

(b) Schematic of the Smoothing, Thermal, Absorbing, Reflective, Conductive, Cosmetic concept for multifunctional skins. ${ }^{13}$

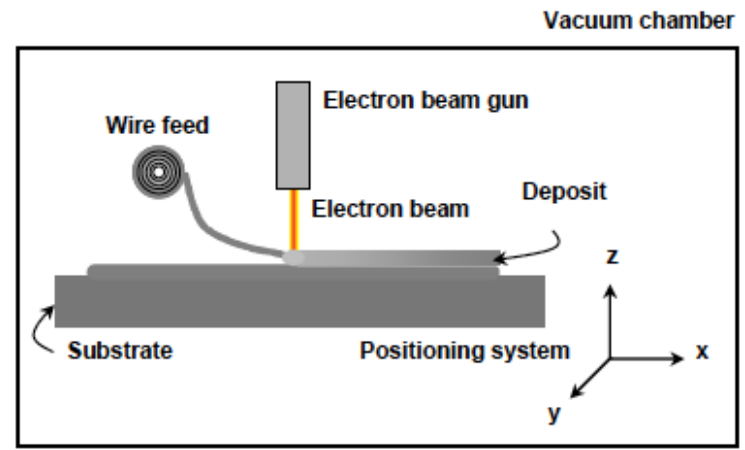

(d) Schematic of an electron beam freeform fabrication system for additive manufacturing. ${ }^{14}$

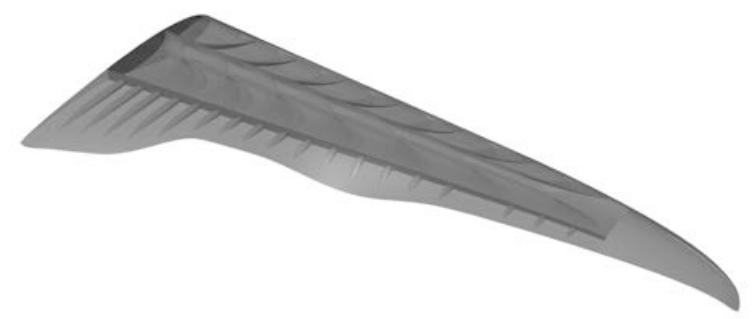

(e) Diagram of an aeroelastically tailored wing structural design with integrated structural controls. ${ }^{14}$

Figure 2. Concepts and technologies for the reduction of vehicle weight. 


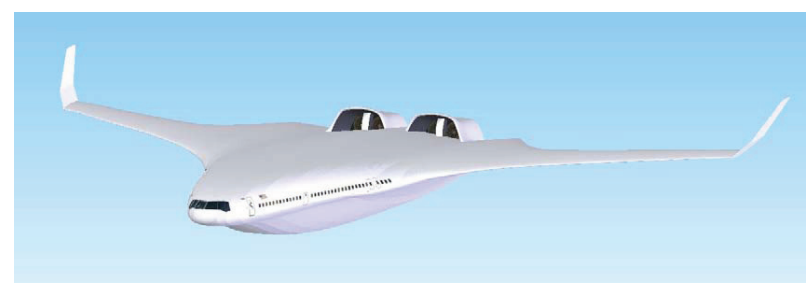

(a) Hybrid wing body configuration with reduced "wetted" area and elliptical span-wise lift distribution during cruise. ${ }^{6}$

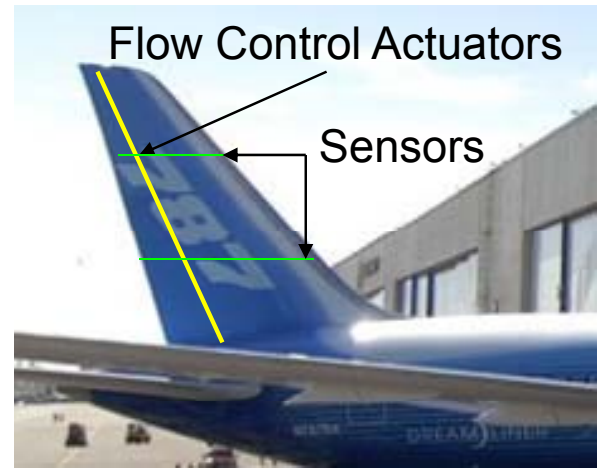

(c) Notional concept to augment rudder performance with active flow control. ${ }^{16}$

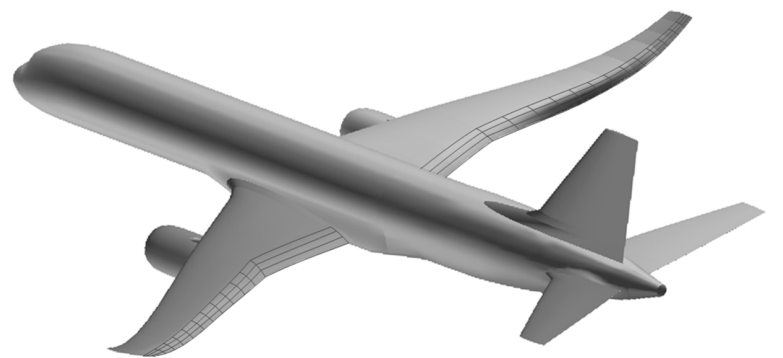

(e) Elastically Shaped Aircraft Concept with Variable Camber Continuous Trailing Edge Flap. ${ }^{18}$

Figure 3. Concepts and technologies to increase the ratio of lift over drag through the reduction of drag.

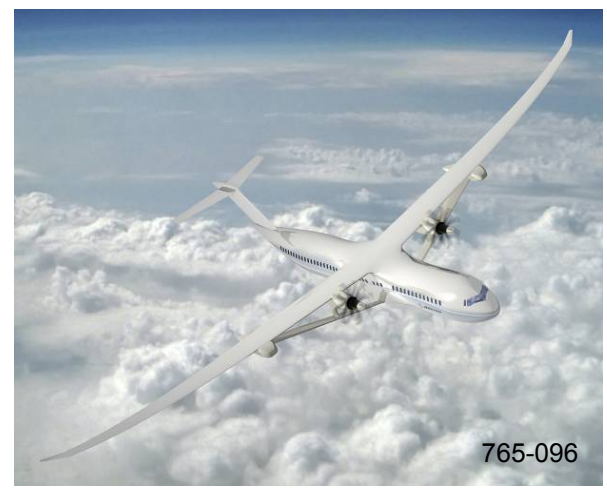

(b) Truss-brased wing configuration with a large wing span and high aspect ratio wings. ${ }^{5}$

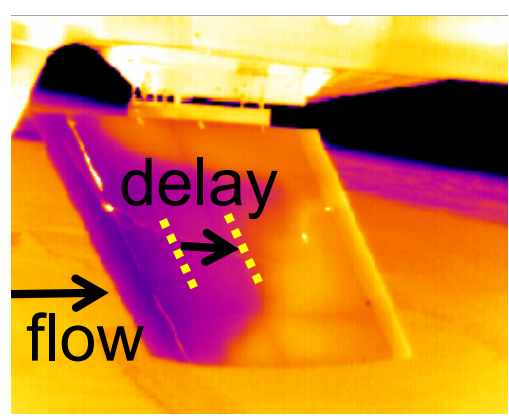

(d) Image showing the delay of transition from laminar to turbulent flow due to discrete roughness elements at low Mach and Reynolds number conditions.

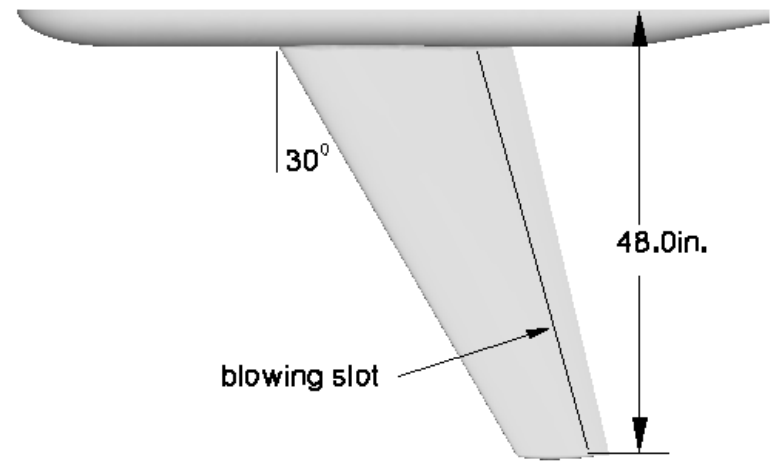

(f) Depiction of the Fundamental Aerodynamics Subsonic/Transonic-Modular Active Control semi-span model used to evaluate the effectiveness of circulation control for drag reduction during cruise conditions. ${ }^{19}$ 


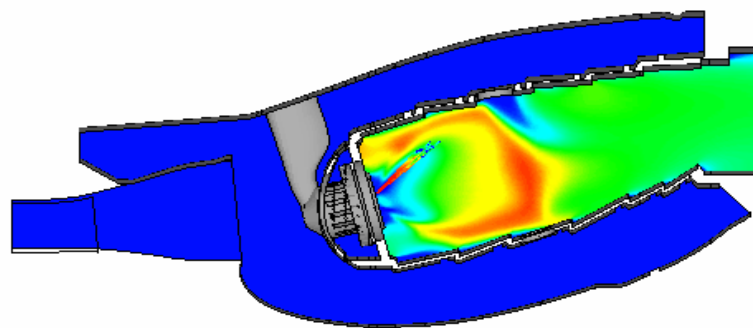

(a) Combustor concept utilizing Ceramic Matrix Composites and Environmental Barrier Coating systems for the combustion liner. ${ }^{21}$

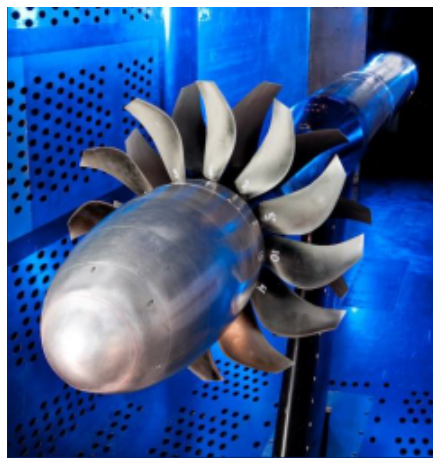

(c) Open Rotor Propulsion Rig installed in a NASA low speed wind tunnel. ${ }^{20}$

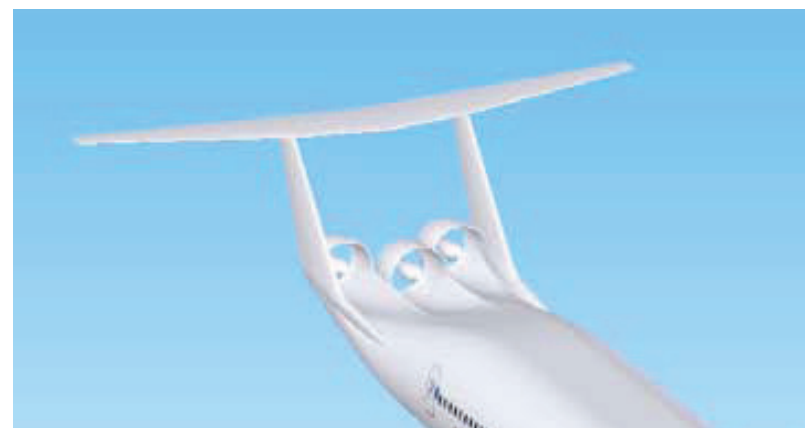

(e) Embedded engines located on the aft of the double-bubble configuration for boundary layer ingestion. ${ }^{6}$

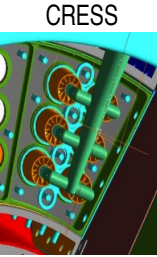

Counter- Rotating Externally Staged Swirler Concept

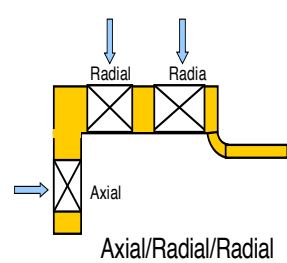

Mixer Concept

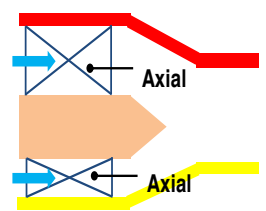

Dual Main Mixer Concept (b) Drawing of candidate lean burn injector/mixer concepts. ${ }^{20}$

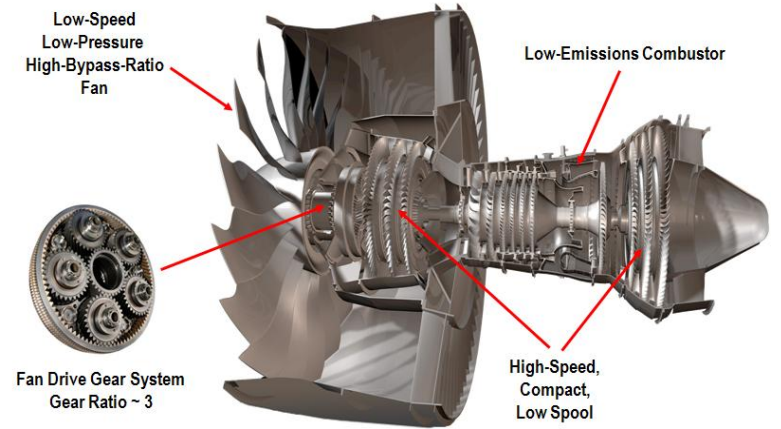

(d) Diagram highlighting research technology areas for an ultra-high bypass ratio geared turbofan. ${ }^{23}$

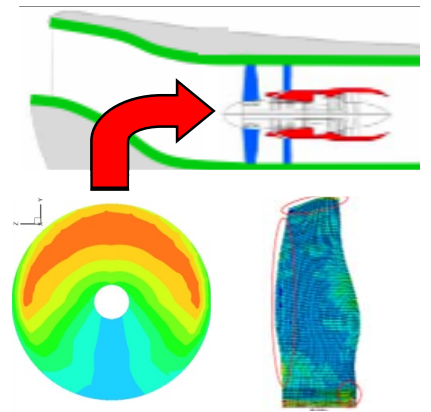

(f) Diagram depicting research to enable embedded systems, including an aeroelastic analysis of fan blades due to inlet distortion and composite fan blade design with aeroelastic tailoring. ${ }^{10,24}$

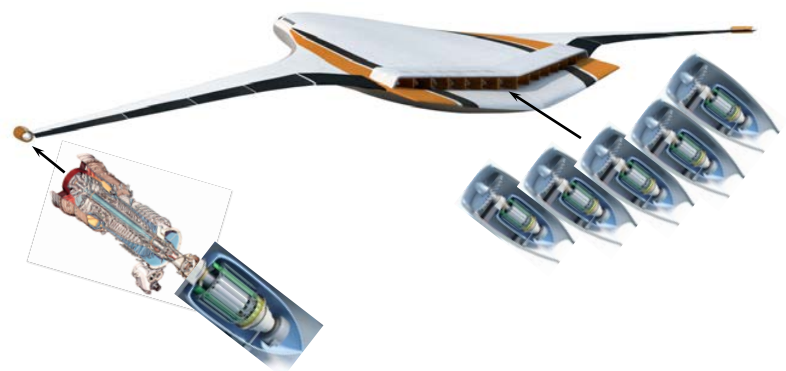

(g) Diagram of the turbo-electric distributed propulsion concept, as applied to a hybrid wing body configuration. ${ }^{24}$

Figure 4. Concepts and technologies for the reduction of thrust specific fuel consumption. 
open rotor systems (Fig. 4(c)). The counter-rotating open rotor systems must be matured to lower noise generation, which is a driving factor in development since noise suppression is not provided by a nacelle. ${ }^{20,23}$ Ultra-high bypass ratio concepts, including geared turbofan (Fig. 4(d)), are also being matured through the development of small, high density cores that will enable higher bypass ratio engines without impacting the engine diameter, drag, or weight. ${ }^{20,24}$ Another concept under investigation is embedded engines. Embedded engines ingest boundary layer flows for improvements in propulsive efficiency and also offer drag reduction benefits (Fig. 4(e)). The research emphasis is on integrated inlet/fan embeddded systems that minimize the loss in fan performance and stability. ${ }^{20}$ One such effort is exploring the design of lightweight fan blades utilizing aeroelastic tailoring to withstand the high dynamic stresses resulting from the embedded inlet distortion (Fig. 4(f)). ${ }^{10,24}$

Hybrid electric engine concepts also aim to improve thrust specific fuel consumption, with the turboelectric distributed propulsion concept promising improvements in both thermal and propulsive efficiency (Fig. 4(g)). ${ }^{9}$ Development efforts to enable the turbo-electric distributed propulsion concept include the development of superconducting material, superconducting motors, cryo-inverters, and cryo-coolers. ${ }^{24}$

\section{System-level Efficiency}

\section{III.A. Factors Contributing to System Efficiency}

System-level efficiency refers to the ability of airports and airspace to accommodate air traffic demand, which corresponds to total throughput of the air transportation system rather than fuel efficiency. As such, many of the operational inefficiencies from the perspective of vehicle efficiency are imposed by air traffic controllers to increase system-level efficiency. Today, system-level efficiency is limited by the infrastructure and procedures that allow the air transportation system to function, and by the uncertainty in the flight environment that affects those procedures.

While the air transportation system has evolved over the years to accommodate the growth of aviation, the system relies on an infrastructure and set of procedures that are becoming strained by high demand. Air travel is limited by the number of aircraft within a predefined sector and the mission operations an aircraft is permitted to execute. Since air traffic controllers are responsible for the safe flow of aircraft through a sector with only limited information about each aircraft and limited computer support systems, the controller's cognitives limitations restrict the number of aircraft within the sector. ${ }^{25}$ Similarly, a dependence on voice radio systems for the communication of instructions and clearances between air traffic controllers and pilots limits the complexity and number of communications. As a result, current operations remain highly constrained, leaving margins for improvement to air traffic flow and system-level efficiency. Required spacing between aircraft also limits the density of aircraft and total capacity of the airspace. Spacing standards between aircraft are set to 3 miles for inland flights and 5 miles for oceanic flights to account for uncertainty in aircraft location introduced by the use of surveillance radar to track aircraft. The terminal area has additional constraints. Airport infrastructure, including runways, taxiways and ramps, limits the movement of aircraft into, around, and out of the airport. Nearby airports and interactions with associated traffic flows also limit aircraft movement within the terminal area. Furthermore, environmental concerns, such as noise and emissions, are limiting growth of air travel at certain airports

Uncertainty in the flight environment, including the presence and severity of weather and aircraftgenerated wake turbulence, also impedes throughput. Weather en-route that may present a hazard for aircraft requires traffic to be rerouted in-flight or delayed prior to departure. Uncertainty in the weather and weather forecast requires large margins of safety between the inclement weather and aircraft, leading to reroutes that may be excessive. Congestion in sectors with good weather ultimately limits the throughput of the entire air transportation system. Poor visibility and weather hazards in the terminal area often add additional spacing requirements or completely stop operations. Incoming and outgoing flights are subsequently put on hold, delayed or canceled until the weather is known to be safe. Due to the risk and uncertain nature of wake turbulence generated by aircraft, wake imposed spacing standards between aircraft in the terminal area becomes another limiting factor on throughput. These spacing standards are dependent on the aircraft types and sizes and on runway configurations, and typically range from 4 to 6 miles.

The effects of these factors, combined with high demand, can culminate into vast decreases in systemlevel efficiency and vehicle efficiency. In fact, it was found that domestic air traffic delays in 2007 resulted in a total cost of $\$ 41$ billion and delayed flights consumed about 740 million additional gallons of jet fuel. ${ }^{26}$ 


\section{III.B. Next Generation Air Transportation System}

The Next Generation Air Transportation System, or NextGen, is a vision shared by the Joint Planning and Development Office, Federal Aviation Administration, and NASA that describes the future air transportation system in the United States. ${ }^{27,28}$ Advancements introduced in NextGen will improve system-level efficiency and vehicle efficiency by increasing throughput, capacity, and flexibility, and by allowing aircraft to operate at their optimal conditions. A conceptual illustration of NextGen is shown in Figure 5.

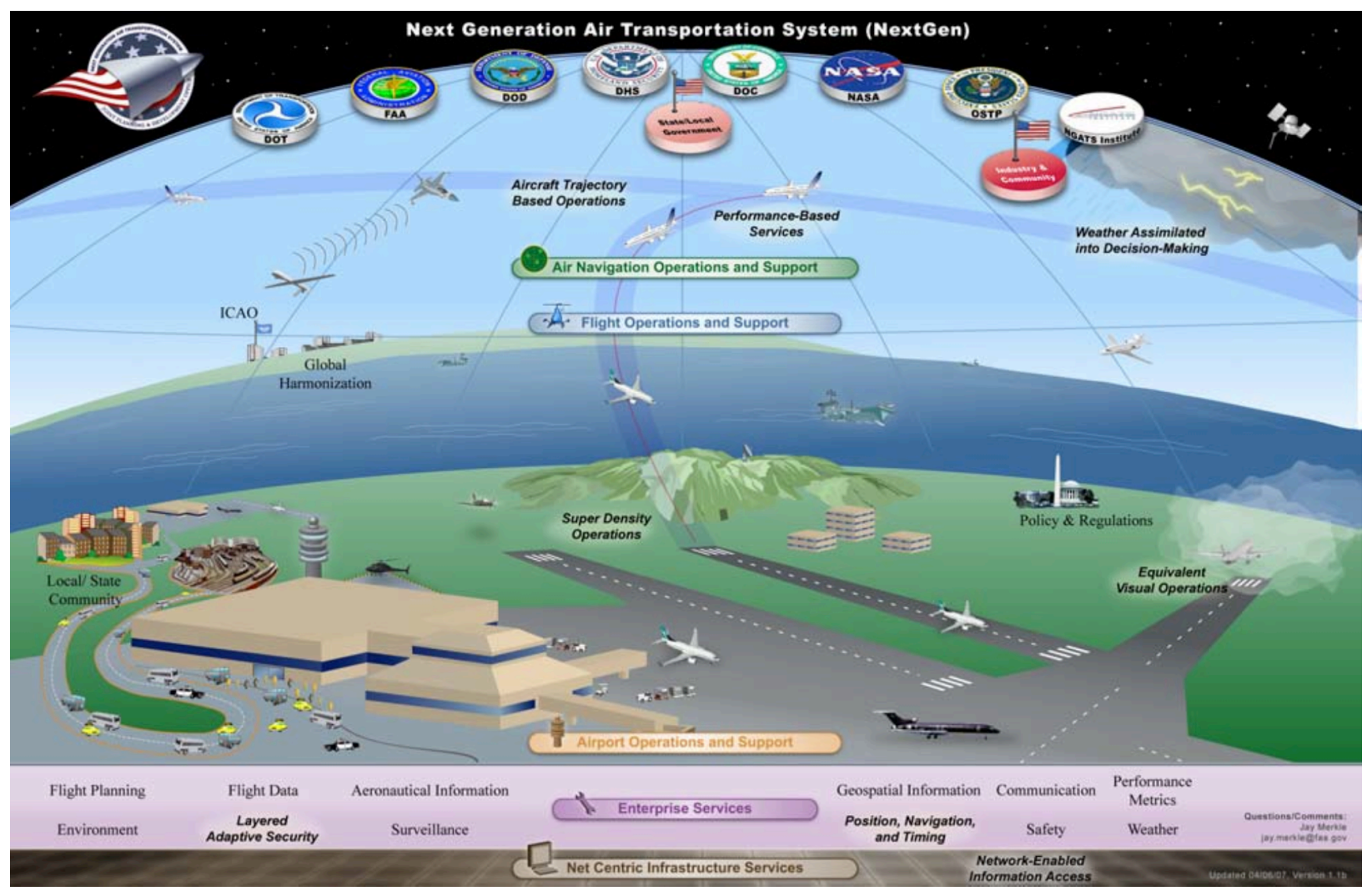

Figure 5. Conceptual illustration of NextGen. ${ }^{27}$

Technologies onboard and tools on the ground will enable better information exchange, communication between between air traffic controllers and pilots, and safe, precision operations by aircraft. The reliance on radar systems and voice communication is expected to end with the adoption of Automatic Dependent Surveillance-Broadcast (ADS-B) technology. ADS-B is an on-board technology that derives aircraft location information from a Global Navigation Satellite System, similar to the Global Positioning System, and provides greater positional accuracy and integrity than the current radar system. ${ }^{29}$ The aircraft location, along with additional information such as aircraft type, altitude, speed, heading, climb or descent rates, flight ID and intent, can be sent by ADS-B to ground stations and properly equipped aircraft within 200 miles, increasing awareness within the air transportation system. ${ }^{29}$ As a result, information is available for air/ground integrated technologies to provide advisories, air traffic controller to make more informed decisions, and pilots to eventually provide self-spacing and self-separation.

Integrated strategic and tactical planning tools for air traffic management will lead to improvements in surface operations, departures, flow and airspace planning, en route operations with weather avoidance, and dense terminal arrivals. Airport surface operations will be improved by information sharing and coordination among airport operators, flight operators and air traffic control facilitated by tools that provide control advisories to reduce overall delay on the surface. Algorithms pursued for airport surface operations management, such as Spot and Runway Departure Advisor with Collaborative Decision Making, will meter departure aircraft to reduce the number of aircraft in taxiways and runway queues and attempt to hold aircraft at the gate or preassigned holding pads with engines off. ${ }^{30}$ The sequence of aircraft arriving and departing will also be optimized to minimize delay. Planning tools, such as the Combined Arrival/Departure 
Scheduler, will consider minimum wake vortex separation and estimated time of operations in advising times of arrivals and departures at an airport. ${ }^{31}$ Departure times will also be planned to allow departing aircraft to efficiently merge into constrained en route streams of air traffic using tools such as the Precision Departure Release Capability. ${ }^{32}$

En route, traffic flow management will benefit from integrated traffic flow and weather models, trajectory planning tools, and more accurate conflict detection and resolution algorithms available to air traffic controllers and pilots. The integration of traffic flow and weather models, for example, will enable aircraft to be assigned more efficient departure delays and routes around weather. In flight, updated weather information will be used to find more direct routes from an aircraft's current location to a subsequent location on the aircraft's flight plan. These new routes, called dynamic weather routes, will save time and alleviate congestion when the airspace is constrained by weather. ${ }^{33}$ Further relief for highly constrained areas will be provided by the concept of dynamic airspace configurations, which represents an airspace structure that can adapt to take advantage of available facilities and controllers to accommodate fluctuating demand. ${ }^{34}$

Tailored operations will also be more prominent in NextGen. Optimized descent profiles, referred to as Continuous Descent Approaches (CDAs), are already implemented at a few airports in the United States, but are only feasible during periods of low to moderate traffic demand. ${ }^{35}$ Controller support tools and display enhancement will enable controllers to manage arrivals that satisfy time-based metering constraints and allow the execution of CDAs and other tailored operations under high traffic demand. The tools and display enhancements will range from early/late display indicators that augment timelines already used in air traffic control, ${ }^{36}$ to slot marker circle displays that provide spatial information on where an aircraft should be in comparison to the actual location, ${ }^{36}$ to advisories that provide controllers recommendations with speed, ${ }^{36}$ altitude, and path stretching solutions ${ }^{37}$ that will keep aircraft on their assigned schedules and maintain safe separation.

\section{Relationship between the Air Transportation System, Aircraft, and Efficiency}

While vehicle efficiency corresponds the fuel usage of an aircraft and system-level efficiency corresponds to the total throughput of the air transportation system, the interactions between the air transportation system and aircraft can limit both vehicle and system-level efficiency. Operational constraints imposed by the air transportation system influence an aircraft's vehicle efficiency. Meanwhile, operational capabilities of an aircraft influence the air transportation system's system-level efficiency. This relationship is depicted in Figure 6.

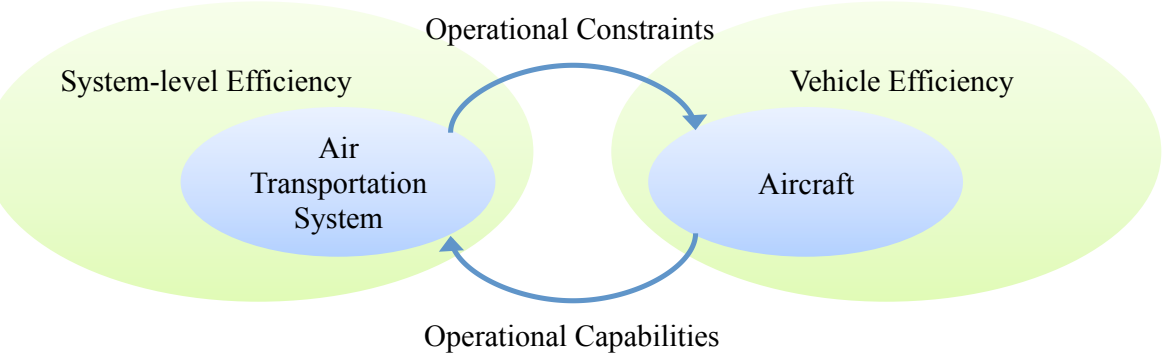

Figure 6. Diagram depicting the relationship between the air transportation system, aircraft, and efficiency.

For a given aircraft and destination, an optimal mission profile, path, and set of operating conditions exists to optimize vehicle efficiency. Deviations from this optimal mission, in the form of operational constraints imposed by the air transportation system, increase fuel usage and diminish the aircraft's efficiency by increasing drag, increasing thrust specific fuel consumption, and/or increasing the total time in operation, as discussed in Section II. Typical operational constraints include delays on the surface, non-wind-optimal routes, rerouting, vectors, holds, speed changes, altitude constraints, and vertical profiles. Fewer operational constraints are expected in NextGen, allowing aircraft to execute optimal missions and tailored operations, thus improving vehicle efficiency. 
One goal of NextGen is to accommodate a highly diverse aircraft fleet, yet aircraft operational capabilities will continue to influence the system-level efficiency of the air transportation system. Traffic flow is dependent on the sequencing, spacing and routing of aircraft. These factors must be in accordance with an aircraft's ability to maneuver, an aircraft's wake generation characteristics, and an aircraft's sensitivity to wake turbulence and weather. These aircraft operational capabilities are discussed further in Section IV.B.

\section{IV.A. Influence of Air Transportation System Operational Constraints on Aircraft Design}

Improved throughput and tailored operations in NextGen are expected to first impact aircraft operational decisions, followed by the design of aircraft concepts. Once confidence is gained in the ability of an aircraft to reliably operate efficiently through the airspace, aircraft operators and pilots are expected to gradually decrease the amount of mission and reserve fuel carried for each flight. The reduction in fuel will reduce the weight of the operating aircraft, thereby improving the aircraft's fuel efficiency. Ultimately, airframe manufacturers are expected to design aircraft to carry less fuel for a particular mission. With a smaller fuel capacity, the aircraft size and weight will reduce accordingly to further improve fuel efficiency of aircraft design concepts. Researchers at Boeing Research and Technology recognized this benefit in a recent study, citing a $17.5 \%$ improvement in fuel per seat for an aircraft designed to a 2030 NextGen mission profile as opposed to a 2008 mission profile. ${ }^{5}$

\section{IV.B. Influence of Aircraft Operational Capabilities on the Air Transportation System}

Aircraft designs, and resulting operational capabilities, have the potential to both improve and adversely impact the system-level efficiency of the air transportation system. In some cases, improvements to system-level efficiency can be obtained through the introduction of diverse mission operations that expedite throughput for aircraft following the different operational procedures and relieve traffic congestion and associated delays for traditional operations. In other cases, improvements to system-level efficiency can be obtained through the uniformity and predictability of aircraft operational capabilities. Designing aircraft with operational capabilities that will benefit the air transportation system, however, may reduce the vehicle's design efficiency by adding weight, decreasing the lift to drag ratio, or increasing thrust specific fuel consumption. Such design considerations include maneuvering performance, wake generation and robustness, and robustness to the effects of weather.

\section{IV.B.1. Maneuvering Performance}

Efficient and effective sequencing and flow of air traffic will be influenced by aircraft maneuvering performance. For arrival and departure at airports, the operational capabilities affecting sequencing and traffic flow include aircraft speed capabilities, turning capabilities, climb rate, descent rate, ability to decelerate in descent, field length requirements, and time and distance required to perform an operation such as deceleration, acceleration, or exit the runway onto a taxiway after touchdown. Aircraft that are agile and able to operate efficiently over a broad range of conditions will be easier for the air transportation system to accommodate into the air traffic flow within the terminal area. Aircraft that require a longer than average time or distance to turn, decelerate or accelerate, however, will require additional spacing between nearby aircraft, thereby limiting throughput. Similar constraints exist en route, where different cruise airspeeds, cruise altitudes, and times and distances required to climb and descent to the optimum altitude introduce complexities in managing air traffic. While designing an aircraft for reduced cruise airspeeds, increased cruise altitudes, and increased time and distance required to climb and descent leads to benefits in vehicle efficiency, ${ }^{5}$ the same design choices in maneuvering performance could impair system-level efficiency by restricting the movement of nearby aircraft.

An integral aspect of improving the capacity of the airspace system is to improve access to airports by "enabling better utilization of existing infrastructure and currently underutilized airports" through new technology and procedures. ${ }^{27}$ One consideration in sizing future aircraft will be the footprint needed for landing and surface operations to ensure the ability to maneuver within existing airport infrastructures. Aircraft length and span, for example, should be responsive to runway, taxiway and ramp configurations at candidate airports. Novel configurations such as the truss-brassed wing with large wing spans will either need to limit wing span in accordance to airport infrastructure or incorporate advanced systems to reduce wing span during surface operations. 
Field length requirement is a unique operational capability in that a diversity in requirements may be advantageous to system-level efficiency, particularly if an aircraft is able to operate in and out of short field lengths. Operation from short field lengths can either allow the use of unused or underutlized runways at major airports ${ }^{38}$ or exploit the metroplex concept of expanding air service to non-hub airports. This allows aircraft with short field length requirements to be sequenced in and out of an airport separately from the remaining air traffic. Aircraft design considerations for reducing field length requirements, however, necessitate additional thrust and lift capabilities that reduce the vehicle efficiency.

\section{IV.B.2. Wake Generation and Robustness}

Reduced separation requirements will be a standard mode of operation for the Next Generation Air Transportation System, both en route and within the terminal area, with the introduction of ADS-B, advanced estimation and planning tools, and conflict resolution technology. The limiting factor in aircraft spacing will be due to wake-based spacing requirements. Researchers in air traffic management would like to see incremental reductions in spacing standards leading to dynamic wake-based spacing. Such reductions in spacing standards would help maximize use of the highest-demand airports and airspace. ${ }^{27}$ Aircraft design concepts that generate modest amounts of wake turbulence and that are able to maintain stable flight when encountering wake turbulence will amplify these benefits by permitting small dynamic wake-based spacing standards. The aircraft design trends towards reductions in weight and induced drag will aid in the reduction of wingtip vortices and resulting wake turbulence. The opposite may be true for future aircraft's robustness to wake turbulence encounters. In favor of system-level efficiency, aircraft design considerations should include active or passive stability techniques for an aircraft's flight dynamics, aerodynamics, structural and propulsion systems while in the presence of a wake turbulence.

Further benefits to airspace capacity and throughput can be gained by grouping aircraft together in a formation. ${ }^{39}$ With proper spacing and positioning within the formation, following transport aircraft can benefit from an average fuel flow reduction of approximately 7 to 8 percent. ${ }^{40}$ More rigorous design considerations, with emphasis on stability and durability of aircraft systems, will be necessary for aircraft in formation with separation optimized for fuel efficiency.

\section{IV.B.3. Robustness to Effects of Weather}

Rather than delaying flights or vectoring flights around inclement weather, the Joint Planning and Development Office has proposed the operational concept that "operators of aircraft equipped with capabilities to mitigate the effects of weather may choose to tactically fly through certain weather-impacted areas." 27 The ability to fly through inclement weather would allow aircraft to maintain efficient point-to-point operations while alleviating air traffic congestion on alternative routes. The top three weather hazards that state-of-the-art aircraft avoid are thunderstorms, extreme turbulence, and severe winds. Another detrimental hazard is volcanic ash. Designing aircraft to fly through these weather hazards is a challenge, ${ }^{41}$ both from an aircraft technology perspective and an aircraft safety perspective. Autonomous transport aircraft may serve as an enabler by alleviating ride quality requirements for aircraft design, yet the design of weather resilient aircraft and flight through weather conditions can be expected to add weight, decrease the lift to drag ratio, or increase thrust specific fuel consumption. Nevertheless, aircraft design concept studies should consider varying degrees of robustness to the effects of weather as a design criteria for improved system-level efficiency.

\section{Impact of Aviation beyond Vehicle and System-level Efficiency}

Sustaining long-term growth in the aviation industry relies on improving the overall impact on the environment and energy use. While improvements in vehicle and system-level efficiency are aimed towards this goal, the impact of aviation spans the entire aircraft life cycle.

One impact of aviation not captured within the definition of vehicle and system-level efficiency is the the energy used, emissions produced, and noise generated while servicing and maintaining aircraft. As new technology is introduced on aircraft, some of these technologies may require regular service. For example, a higher dependence on electrical power may lead to requirements to recharge or exchange batteries on the ground; laminar flow wings may require regular cleaning; and lightweight, flexible structures may require regular inspection. In response to these requirements, airport infrastructure will grow. Attention will be 
needed to ensure the growth of airport infrastructure is done in an energy and environmentally conscious manner. ${ }^{28}$ Further attention should be given during the design of aircraft concepts and technologies to minimize additional requirements imposed on airport infrastructure.

\section{Acknowledgments}

This paper was developed by members of the Subsonic Fixed Wing Project, and now Fixed Wing Project, within the Fundamental Aeronautics Program of the NASA Aeronautics Research Mission Directorate.. The authors thank Parimal Kopardekar, Project Manager of the Concepts and Technology Development Project within the Airspace Systems Program, and John Kaneshige for the valuable discussions and insight that influenced this paper.

\section{References}

1 "The Economic Impact of Civil Aviation on the U.S. Economy," August 2011, U.S. Department of Transportation and Federal Aviation Administration

2 "National Transportation Statistics," 2011, U.S. Department of Transportation.

3 "ATA Cost Index for U.S. Passenger Airlines: 3Q 2011," Airlines for America.

${ }^{4}$ Mattingly, J. D., Elements of Gas Turbine Propulsion, McGraw-Hill, New York, 1996.

${ }^{5}$ Bradley, M. K., Droney, C. K., "Subsonic Ultra Green Aircraft Research: Phase I Final Report," NASA/CR-2011-216847, April 2011

${ }^{6}$ Greitzer, E. M., Bonnefoy, P. A., De la Rosa Blanco, E., Dorbian, C. S., Drela, M., Hall, D. K., Hansman, R. J., Hileman, J. I., Liebeck, R. H., Levegren, J., Mody, P., Pertuze, J. A., Sato, S., Spakovszky, Z. S., Tan, C. S., Hollman, J. S., Duda, J. E., Fitzgerald, N., Houghton, J., Kerrebrock, J.L., Kiwada, G. F., Kordonowy, D., Parrish, J. C., Tylko, J., Wen, E. A., Lord, W. K., "N3 Aircraft Concept Designs and Trade Studies, Final Report," NASA/CR-2010-216794/VOL1, December 2010

${ }^{7}$ Cameron, Douglas and Princen, Norman, "Control Allocation Challenges and Requirements for the Blended Wing Body," AIAA Guidance, Navigation and Control Conference and Exhibit, AIAA, Denver, Colorado, August 2000, AIAA-2000-4539

${ }^{8}$ Roman, D., Allen, J. B., and Liebeck, R. H., "Aerodynamic Design Challenges of the Blended-Wing-Body Subsonic Transport," AIAA Applied Aerodynamics Conference, AIAA, Denver, Colorado, August 2000, AIAA-2000-4335

${ }^{9}$ Felder, J., Brown, G., Kim, H., Chu, J., "Turboelectric Distributed Propulsion in a Hybrid Wing Body Aircraft," 20 th ISABE Conference, Götenberg, Sweden, 12-16 Sept., 2011, ISABE-2011-1340

${ }^{10}$ Taminger, K. M., "Technical Challenges to Reducing Subsonic Transport Weight," $50^{\text {th }}$ AIAA Aerospace Sciences Meeting, AIAA, Nashville, Tennessee, January 2012, Oral/Visual Presentation

${ }^{11}$ Velicki, A., Thrash, P., Jegley, D., "Airframe Development for the Hybrid Wing Body Aircraft," 4 tth $^{\text {AIAA Aerospace }}$ Sciences Meeting, AIAA, Orlando, Florida, AIAA 2009-932

${ }^{12}$ Bezos-O'Connor, G. M., Mangelsdorf, M. F., Maliska, H. A., Washburn, A. E., Wahls, R. A., "Fuel Efficiencies Through Airframe Improvements," $3^{\text {rd }}$ AIAA Atmospheric Space Environments Conference, AIAA, Honolulu, Hawaii, June 2011, AIAA 2011-3530

${ }^{13}$ Johnson, V. S., Boone, R. L., Jones, S., Pendse, V., "Initial Feasibility of Protective Skins for Composite Airliners," $54^{\text {th }}$ AIAA/ASME/AHE/ASC Structural, Structural Dynamics, and Materials Conference, AIAA, Boston, Massachusetts, AIAA 2013-1899

${ }^{14}$ Taminger, K. M., Hafley, R. A., "Electron Beam Freeform Fabrication for Cost Effective Near-Net Shape Manufacturing," NASA/TM-2006-214284, March 2006

${ }^{15}$ Rogers, M. M., "Technical Challenges to Reducing Subsonic Transport Drag," $50^{\text {th }}$ AIAA Aerospace Sciences Meeting, AIAA, Nashville, Tennessee, January 2012, Oral/Visual Presentation

${ }^{16}$ Washburn, A., "Drag Reduction Status and Plans - Laminar Flow and AFC," $49^{\text {th }}$ AIAA Aerospace Sciences Meeting, AIAA, Orlando, Florida, January 2011, Oral/Visual Presentation

${ }^{17}$ Malik, M., Liao, W., Li, F., Choudhari, M., $51^{\text {st }}$ AIAA Aerospace Sciences Meeting, AIAA, Grapevine, Texas, January 2013, AIAA 2013-0412

${ }^{18}$ Nguyen, N., Urnes, J., "Aeroelastic Modeling of Elastically Shaped Aircraft Concept via Wing Shaping Control for Drag Reduction," AIAA Atmospheric Flight Mechanics Conference, AIAA, Minneapolis, Minnesota, August 2012, AIAA-2012-4642

${ }^{19}$ Milholen, W. E., Jones, G. S., Chan, D. T., Goodliff, S. L., "High-Reynolds Number Circulation Control Testing in the National Transonic Facility," 50 th AIAA Aerospace Sciences Meeting, AIAA, Nashville, Tennessee, January 2012, AIAA 2012-0103

${ }^{20}$ Suder, K. L., "Overview of the NASA Environmentally Responsible Aviation Project's Propulsion Technology Portfolio," $48^{\text {th }}$ AIAA/ASME/SAE/ASEE Joint Propulsion Conference, Atlanta, Georgia, July-August 2012, AIAA 2012-4038

${ }^{21}$ Grady, J. E., "Overview of CMC Research at NASA Glenn Research Center," $35^{\text {th }}$ Annual Conference on Composites, Materials and Structures, Cape Canaveral, Florida, January 2011

${ }^{22}$ Tacina, K. M., Wey, C., "NASA Glenn High Pressure Low NOx Emissions Research," NASA/TM-2008-214974, February 2008

${ }^{23}$ Hughes, C., "The Promise and Challenges of Ultra High Bypass Ratio Engine Technology and Integration," $49^{\text {th }}$ AIAA Aerospace Sciences Meeting, AIAA, Orlando, Florida, January 2011, Oral/Visual Presentation 
${ }^{24}$ Hathaway, M. D., "Technical Challenges to Reducing Thrust Specific Energy Consumption," 50 ${ }^{\text {th }}$ AIAA Aerospace Sciences Meeting, AIAA, Nashville, Tennessee, January 2012, Oral/Visual Presentation

25 "NASA and the Next Generation Air Transportation System (NextGen)," NASA Aeronautics Research Mission Directorate

${ }^{26}$ Senator Schumer, C. E., Representative Maloney, C. B., "Your Flight Has Been Delayed Again: Flight Delays Cost Passengers, Airlines, and the U.S. Economy Billions," A Report by the Joint Economic Committee Majority Staff, May 2008

${ }^{27}$ Operational Concept for the Next Generation Air Transportation System, Joint Planning and Development Office, Version 3.2

${ }^{28}$ Next Generation Air Transportation System Integrated Plan, Joint Planning and Development Office

${ }^{29}$ Bargsten, C. J., Gibson, M. T., "NASA Innovation in Aeronautics: ADS-B and Airspace Awareness," NASA/TM-2011216987, August 2011

${ }^{30}$ Gupta, G., Malik, W., Jung, Y. C., "An Integrated Collaborative Decision Making and Tactical Advisory Concept for Airport Surface Operations Management," $12^{\text {th }}$ AIAA Aviation Technology, Integration, and Operations Conference, AIAA, Indianapolis, Indiana, September 2012, AIAA 2012-5651

${ }^{31}$ Tyagi, A., Wieland, F., "The Design and Optimization of a Combined Arrival-Departure Scheduler," $12^{\text {th }}$ AIAA Aviation Technology, Integration, and Operations Conference, AIAA, Indianapolis, Indiana, September 2012, AIAA 2012-5697

${ }^{32}$ Engelland, S. A., Capps, A., "Trajectory-Based Takeoff Time Predictions Applied to Tactical Departure Scheduling: Concept Description, System Design, and Initial Observations," $11^{\text {th }}$ AIAA Aviation Technology, Integration, and Operations Conference, AIAA, Virginia Beach, Virginia, September 2011, AIAA 2011-6875

${ }^{33}$ Sheth, K. S., McNally, D., Petersen, J. C., Morando, A. A., Shih, F-T., "Consideration of Strategic Airspace Constraints for Dynamic Weather Routes," $12^{\text {th }}$ AIAA Aviation Technology, Integration, and Operations Conference, AIAA, Indianapolis, Indiana, September 2012, AIAA 2012-5501

${ }^{34}$ Kopardekar, P., Bilimoria, K., Sridhar, B., "Initial Concepts for Dynamic Airspace Configuration," rth AIAA Aviation Technology, Integration and Operations Conference, AIAA, Belfast, Northern Ireland, September 2007, AIAA 2007-7763

${ }^{35}$ Robinson III, J. E., Kamgarpour, M., "Benefits of Continuous Descent Operations in High-Density Terminal Airspace Under Scheduling Constraints," $10^{\text {th }}$ AIAA Aviation Technology, Integration and Operations Conference, AIAA, Fort Worth, Texas, September 2010, AIAA 2010-9115

${ }^{36}$ Kupfer, M., Callantine, T., Martin, L., Mercer, J., Palmer, E., "Controller Support Tools for Schedule-Based TerminalArea Operations," Ninth USA/Europe Air Traffic Management Research and Development Seminar, Berlin, Germany, June 2011

${ }^{37}$ Coppenbarger, R. A., Mead, R. W., Sweet, D. N., "Field Evaluation of the Tailored Arrivals Concept for Datalink-Enabled Continuous Descent Approach," Journal of Aircraft, AIAA, Vol. 46, No. 4, July-August 2009

${ }^{38}$ Couluris, G. J., Hange, C. E., Wardwell, D. A., Signor, D., and Phillips, J., "A Potential Impact Analysis of ESTOL Aircraft on Newark Airport Operations," AIAA Modeling and Simulation Technologies Conference and Exhibit, AIAA, Hilton Head, South Carolina, August 2007, AIAA-2007-6700

${ }^{39}$ Xue, M., Hornby, G., "An Analysis of the Potential Savings from Using Formation Flight in the NAS," AIAA Guidance, Navigation, and Control Conference, AIAA, Minneapolis, Minnesota, August 2012, AIAA 2012-4524

${ }^{40}$ Pahle, J., Berger, D., Venti, M., Duggan, C., Faber, J., Cardinal, K., "An Initial Flight Investigation of Formation Flight for Drag Reduction on the C-17 Aircraft," AIAA Guidance, Navigation, and Control Conference, AIAA, Minneapolis, Minnesota, August 2012, AIAA 2012-4802

${ }^{41}$ Krozel, J., Murphy, J., "Weather Hazard Requirements for NGATS Aircraft," IEEE, 2007 